\title{
Psychoactive Substance Use among Nigerian Secondary School Students: A Review of Current Literature
}

\author{
Hassana Ojonuba Shuaibu ${ }^{1}$,Abdul Rahman Haliza ${ }^{1,2 *}$, Asnarulkhadi Abu Samah ${ }^{1}$ \\ and Nor Afiah Mohd Zulkefli ${ }^{2}$ \\ ${ }^{1}$ Institute for Social Science Studies, Putra Infoport, Universiti Putra Malaysia, 43400 Serdang, Selangor, \\ Malaysia \\ ${ }^{2}$ Faculty of Medicine \& Health Sciences, Universiti Putra Malaysia, 43400 Serdang, Selangor, Malaysia
}

\begin{abstract}
Substance use is a global health issue that may lead to engagement in other risky behaviours, addiction, accidents and non-communicable diseases. In Nigeria, this risky behaviour is becoming an emerging trend among secondary school students. This review was thus carried out to gain an overview of the prevalence and risk factors of substance use among secondary school students in Nigeria. A literature search of articles in Scopus, PubMed and other online databases was conducted for articles published between 2009 to 2019. Sixteen studies met the inclusion criteria. Overall, psychoactive substance ranged from $21 \%$ to $87 \%$. Alcohol consumption was the highest, while the use of tobacco, cannabis, and cocaine was low. The mean age at initiation ranged from 11 to 15 years. Male gender, peer influence, parental factors, individual factors and knowledge on the dangers of psychoactive substance use were common factors associated with substance use among Nigerian secondary school

ARTICLE INFO

Article history:

Received: 10 February 2020

Accepted: 13 November 2020

Published: 25 December 2020

DOI: https://doi.org/10.47836/pjssh.28.4.36

students. School-based interventions should be multifaceted and holistic. More research should be theory-based and conducted in the Northern parts of Nigeria. Future studies should measure other psychological factors that may influence these behaviours to provide more insight into interventions.
\end{abstract}

E-mail addresses:

hasseyshuaibu@gmail.com (Hassana Ojonuba Shuaibu) dr.haliza@upm.edu.my (Haliza Abdul Rahman)

asnarulhadi@gmail.com (Asnarulkhadi Abu Samah)

norafiah@upm.edu.my (Nor Afiah Mohd Zulkefli)

*Corresponding author
Keywords: Adolescent, alcohol, risky behaviour, substance use, secondary school students, tobacco 


\section{INTRODUCTION}

Adolescence comes with biological, cognitive and emotional changes. It is a period of experimentation and discovery and the adoption of new interests and behaviours (Patton et al., 2016). Some of these behaviours include risky behaviours like the use of substances such as tobacco, alcohol and drugs. Studies have reported that substance use in adolescence can be sustained into adulthood, leading to health effects that develop later in life (Patton et al., 2016; Viner et al., 2015).

Psychoactive substance use includes the use of licit substances like alcohol and tobacco, as well as illicit substances like cocaine, codeine/tramadol, and cannabis. There is enough documented evidence on the dangers associated with substance use. For instance, alcohol consumption is associated with alcohol dependence, accidents, diabetes, liver disease, and cancers (Rehm, 2011), while tobacco consumption is linked with tobacco dependence, lung disease, and cardiovascular diseases (Bartal, 2001). Codeine, marijuana and cocaine are addictive and can negatively affect mental health (Henry, 2000).

Among adolescents, the developmental changes occurring during adolescence lead to unique and differential effects among substance users. For example, cocaine has been reported to be more addictive among adolescents due to their neurochemical makeup (Izenwasser, 2005). Alcohol use among adolescents also leads to marked and deleterious changes in brain functioning like memory, attention, and speed in processing information. Marijuana has been linked with poor learning performances and reduced cognitive functioning (Squeglia et al., 2009). Other effects of psychoactive substance use among adolescents include truancy, vandalism, poor academic performance, accidents and injuries, risky sexual behaviour, and life-long addiction (Center for Substance Abuse Treatment, 1999; Whyte et al., 2018).

Despite the damaging outcomes of substance use, there is an increasing rate of substance use among young people globally (Center for Substance Abuse Treatment, 1999). Research conducted in several parts of Nigeria about this phenomenon has shown that Nigeria is no exception. Considering these, the authors aim to design and implement a school-based intervention to reduce the prevalence of this risky behaviour among Nigerian secondary school students. However, there is no current paper summarising and organising findings from the numerous existing studies on psychoactive substance use among Nigerian secondary school students.

This review paper was, therefore written to gain a general overview of the current status and risk factors of substance use among secondary school students in the country. This will provide insight into the effective development and implementation of school-based substance use interventions and be an excellent resource for other academicians and researchers. 


\section{METHODS}

\section{Literature Search}

A thorough search of PubMed, Scopus, AJOL and Google scholar was conducted to find articles on psychoactive substance use among secondary school students. The authors searched titles and abstracts of literature using a combination of related terms and keywords ("risk behaviour", "smoking" "cigarette" "alcohol" "substance use" "psychoactive substance", "adolescent", "teen", “teenager", “young”, "secondary school" youth, Nigeria,) and appropriate Boolean terms. The authors also manually searched references of other studies to find related literature. Figure 1 shows a flow chart of the literature search conducted in this study.

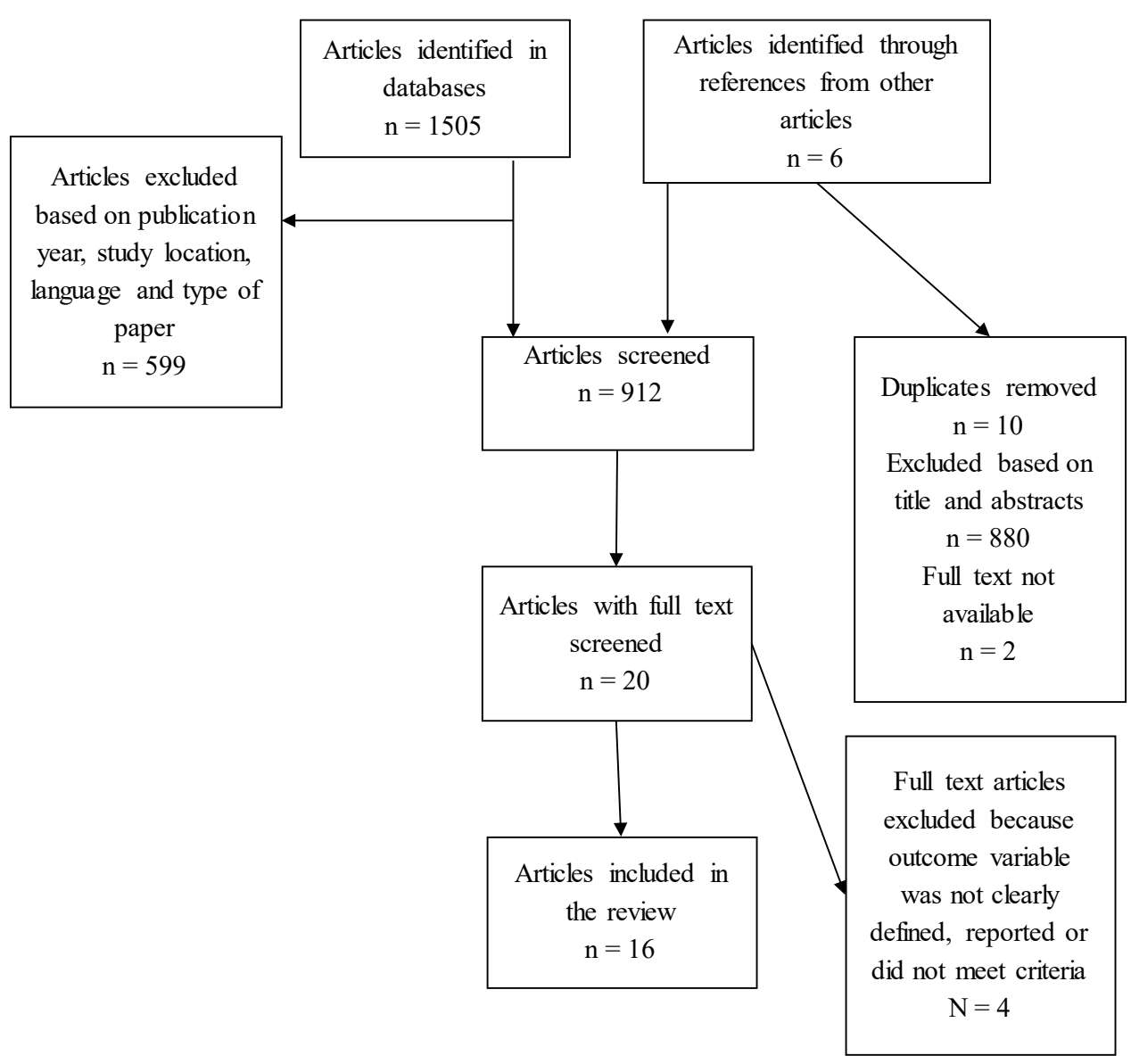

Figure 1. Flow chart diagram showing the literature search for this study 


\section{Selection Criteria}

The authors selected studies that measured the lifetime or current use of one or more of the following psychoactive substances; alcohol, tobacco, codeine, cocaine, and cannabis. The authors reviewed only studies published from 2009, conducted in Nigeria, and among secondary school students. Studies that reported the risk factors of any of the above-mentioned psychoactive substances were also included. The authors excluded reviews, letters, meta-analyses, studies conducted in non-English languages, in multiple countries, focused on one gender and where the full text was not available even after a thorough internet search. Finally, articles with obvious methodological flaws, e.g. failure to define how the outcome variable was measured were excluded.

\section{RESULTS}

\section{Study Characteristics}

Sixteen articles met the inclusion criteria for this review. Table 1 shows the characteristics and findings of the studies reviewed.

\section{Psychoactive Substances Measured in the Studies}

Seven articles measured tobacco or cigarette use (Arute et al., 2015; Chinawa et al., 2014; Itanyi et al., 2018; Odukoya et al., 2013; Okagua et al., 2016; Raji et al., 2018), one article measured both alcohol and tobacco use (Olugbenga-Bello et al., 2014), and eight studies measured the use of any of alcohol, tobacco, cocaine and cannabis as psychoactive substance use (Alex-Hart et al., 2015; Atoyebi \& Atoyebi, 2013;
Famuyiwa et al., 2011; Idowu et al., 2018; Igwe, 2009; Manyike et al., 2016; Ogunsola \& Fatusi, 2017; Oshodi et al., 2010).

\section{Data Collection Instruments}

Four authors used a modified World Health Organization (WHO) Student Drug Use questionnaire as their data collection tool (Igwe, 2009; Manyike et al., 2016; Ogunsola \& Fatusi, 2017; Oshodi et al., 2010). Four authors used the Global Youth Tobacco Survey questionnaire to collect data on tobacco consumption (Itanyi et al., 2018; Odukoya et al., 2013; Okagua et al., 2016; Raji et al., 2013). One author used the Health Kids Colorado Questionnaire (Chinawa et al., 2014). The remaining authors structured their own questionnaires (Alex-Hart et al., 2015; Arute et al., 2015; Atoyebi \& Atoyebi, 2013; Famuyiwa et al., 2011; Idowu et al., 2018; Odey et al., 2012; Olugbenga-Bello et al., 2014).

\section{Study Population}

In ten studies, data was collected from students aged between 10 to 19 years (Chinawa et al., 2014; Famuyiwa et al., 2011; Igwe, 2009; Itanyi et al., 2018; Manyike et al., 2016; Odey et al., 2012; Ogunsola \& Fatusi, 2017; Okagua et al., 2016; Olugbenga-Bello et al., 2014; Raji et al., 2013). In five studies, data was collected from students aged between 10 to 20 years and above (Alex-Hart et al., 2015; Arute et al., 2015; Atoyebi \& Atoyebi, 2013; Odukoya et al., 2013). For one study, the age range of the study participants was not indicated (Idowu et al., 2018). 
Psychoactive Substance Use among Nigerian Secondary School Students

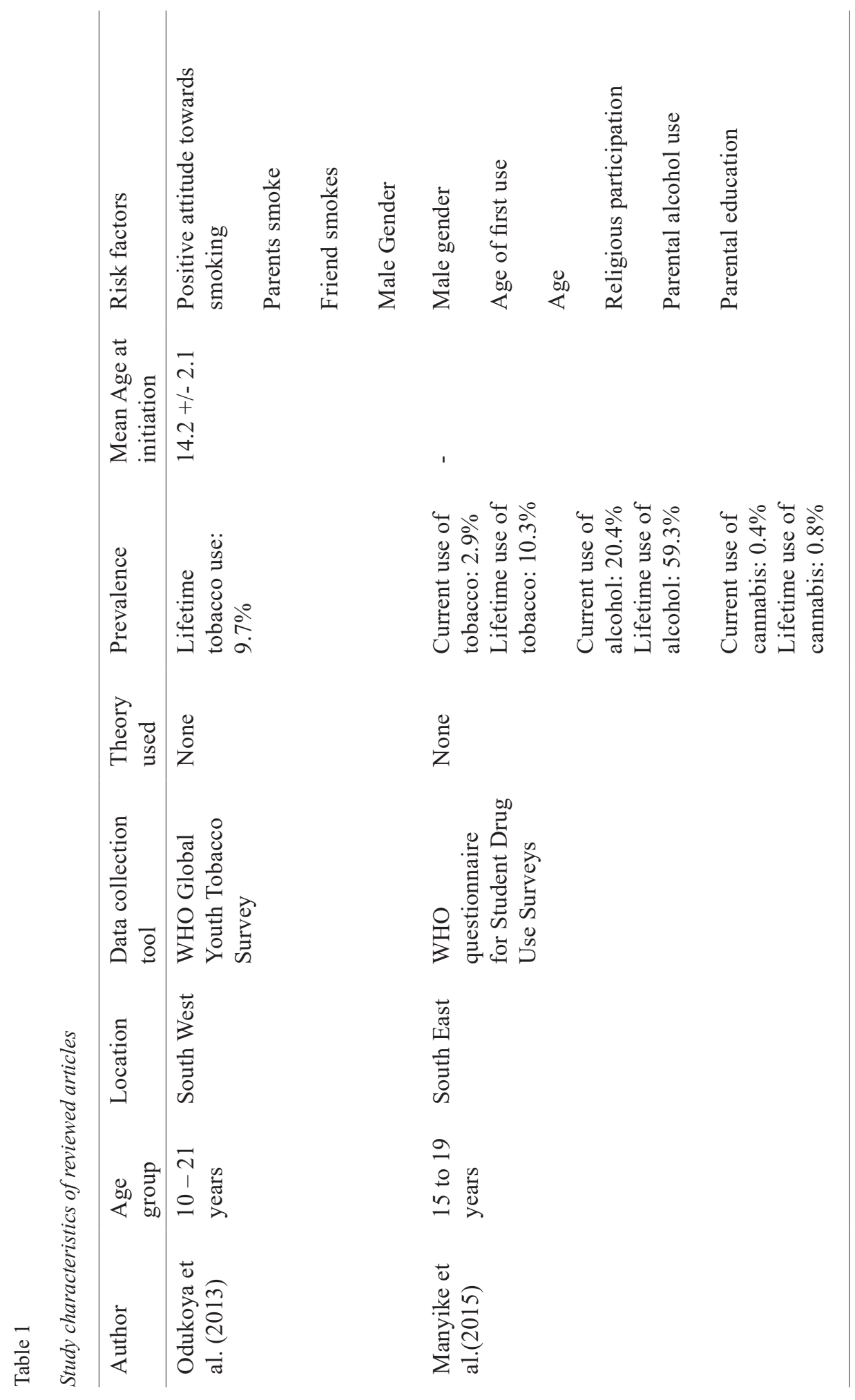


Hassana Ojonuba Shuaibu, Abdul Rahman Haliza, Asnarulkhadi Abu Samah and Nor Afiah Mohd Zulkefli

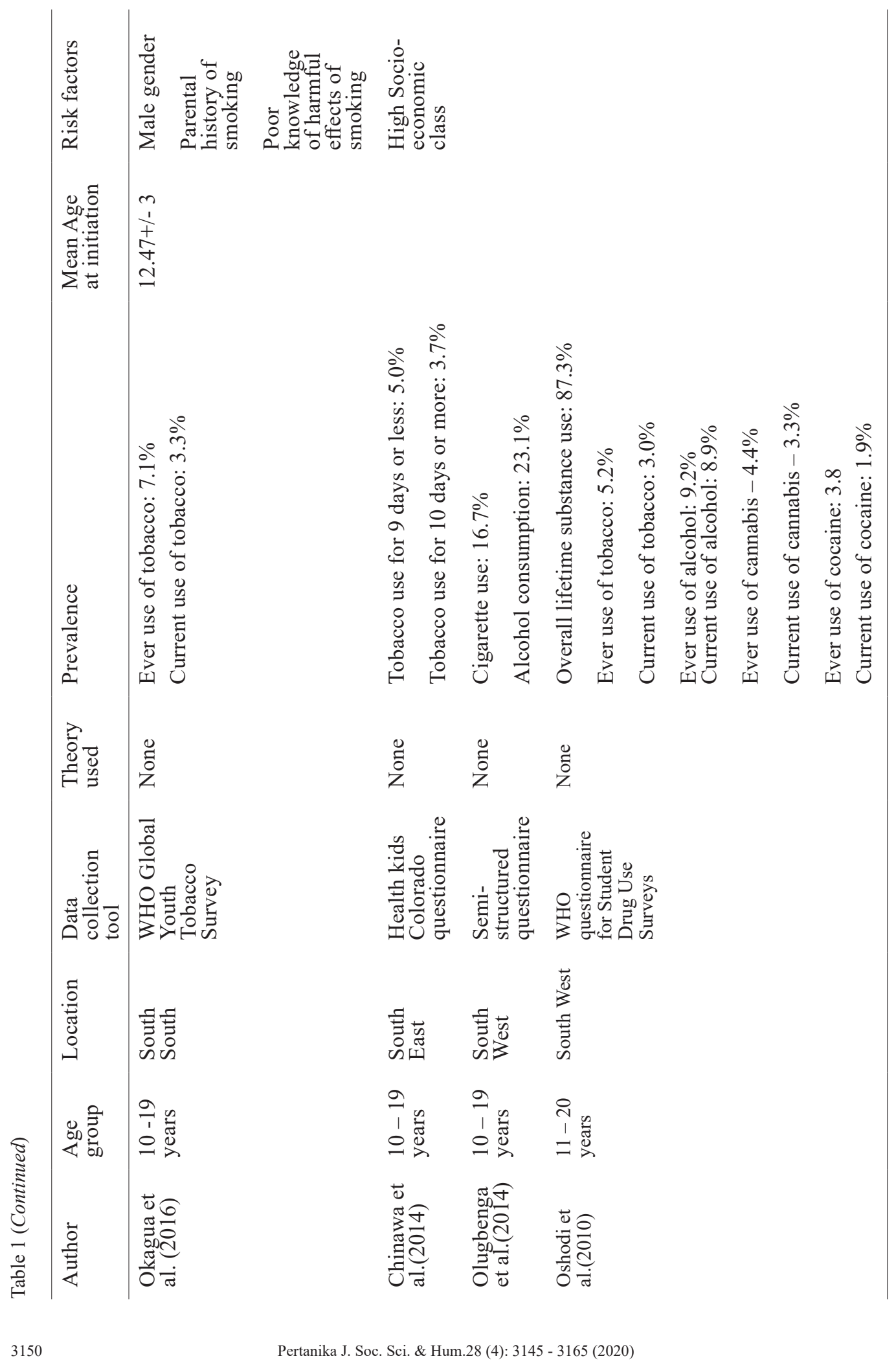


Psychoactive Substance Use among Nigerian Secondary School Students

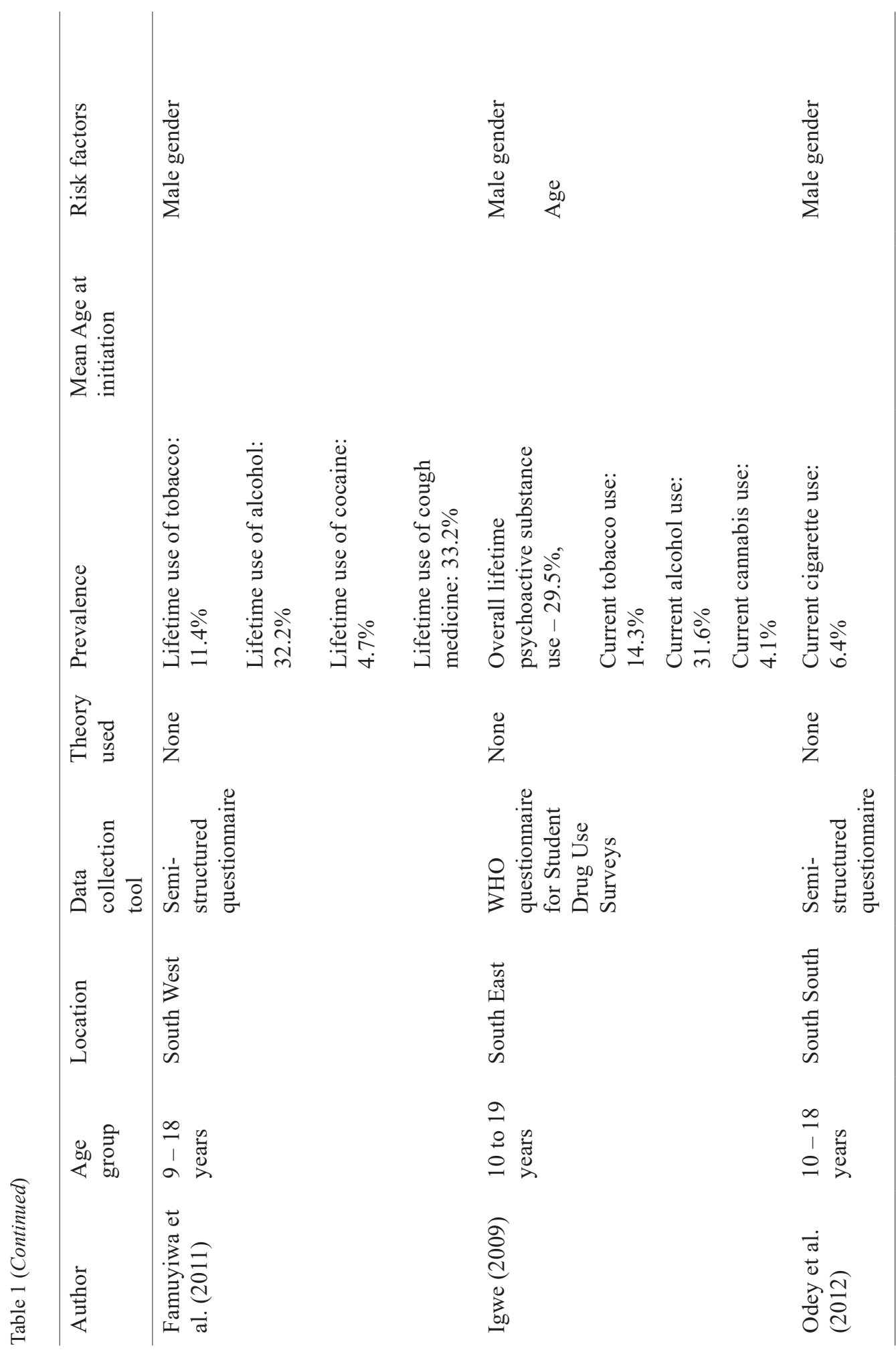


Hassana Ojonuba Shuaibu, Abdul Rahman Haliza, Asnarulkhadi Abu Samah and Nor Afiah Mohd Zulkefli

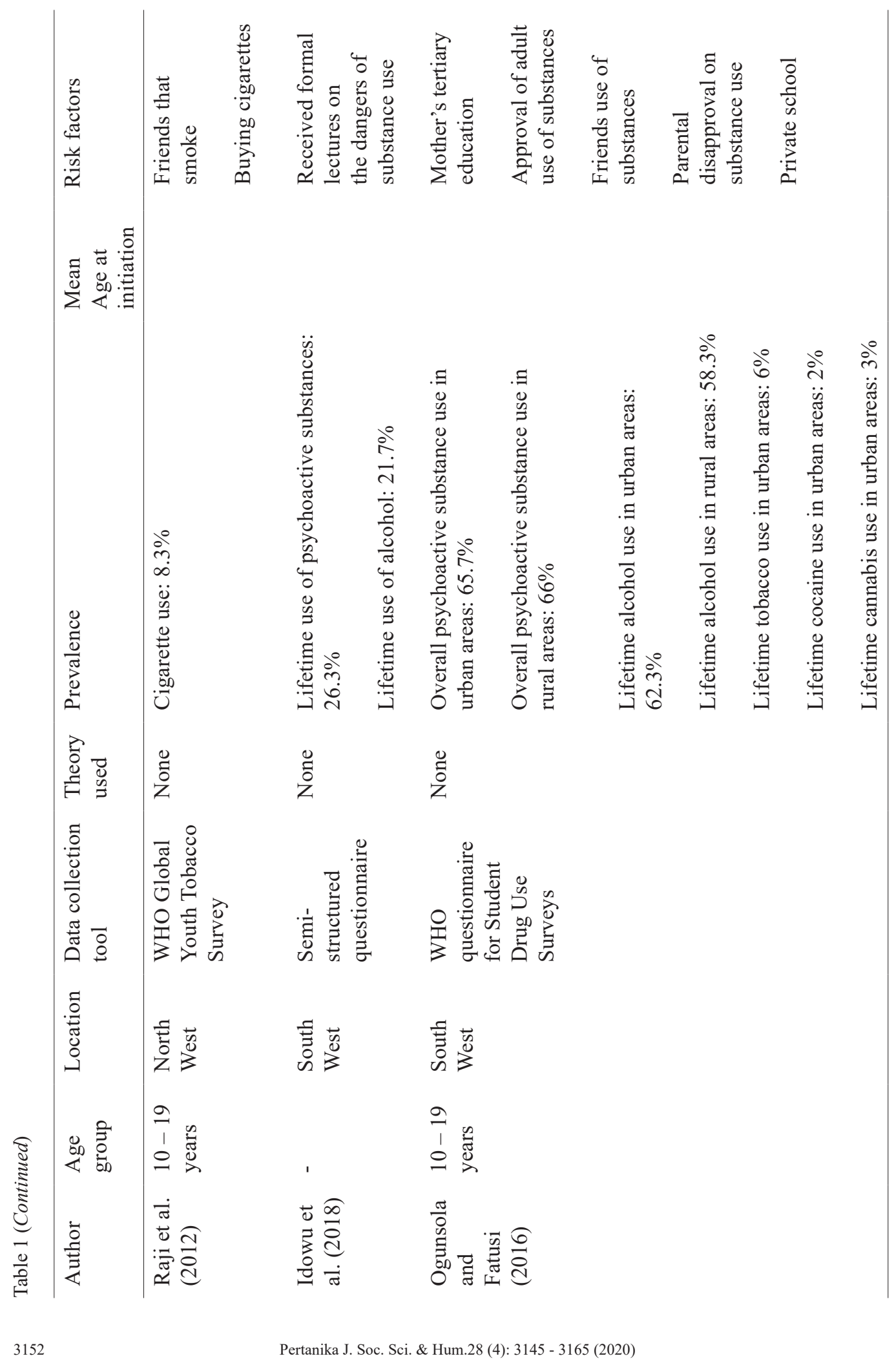


Psychoactive Substance Use among Nigerian Secondary School Students

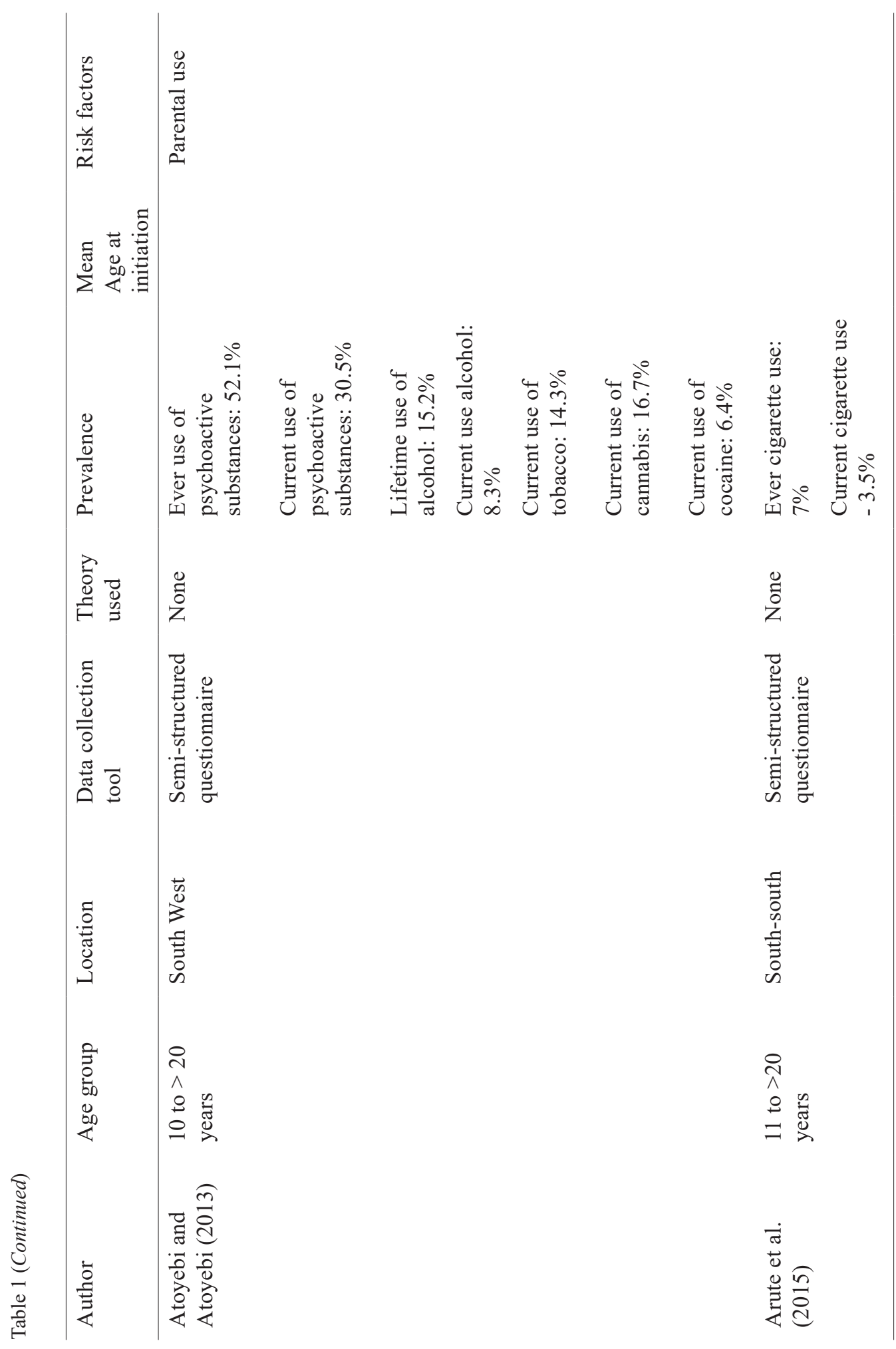


Hassana Ojonuba Shuaibu, Abdul Rahman Haliza, Asnarulkhadi Abu Samah and Nor Afiah Mohd Zulkefli

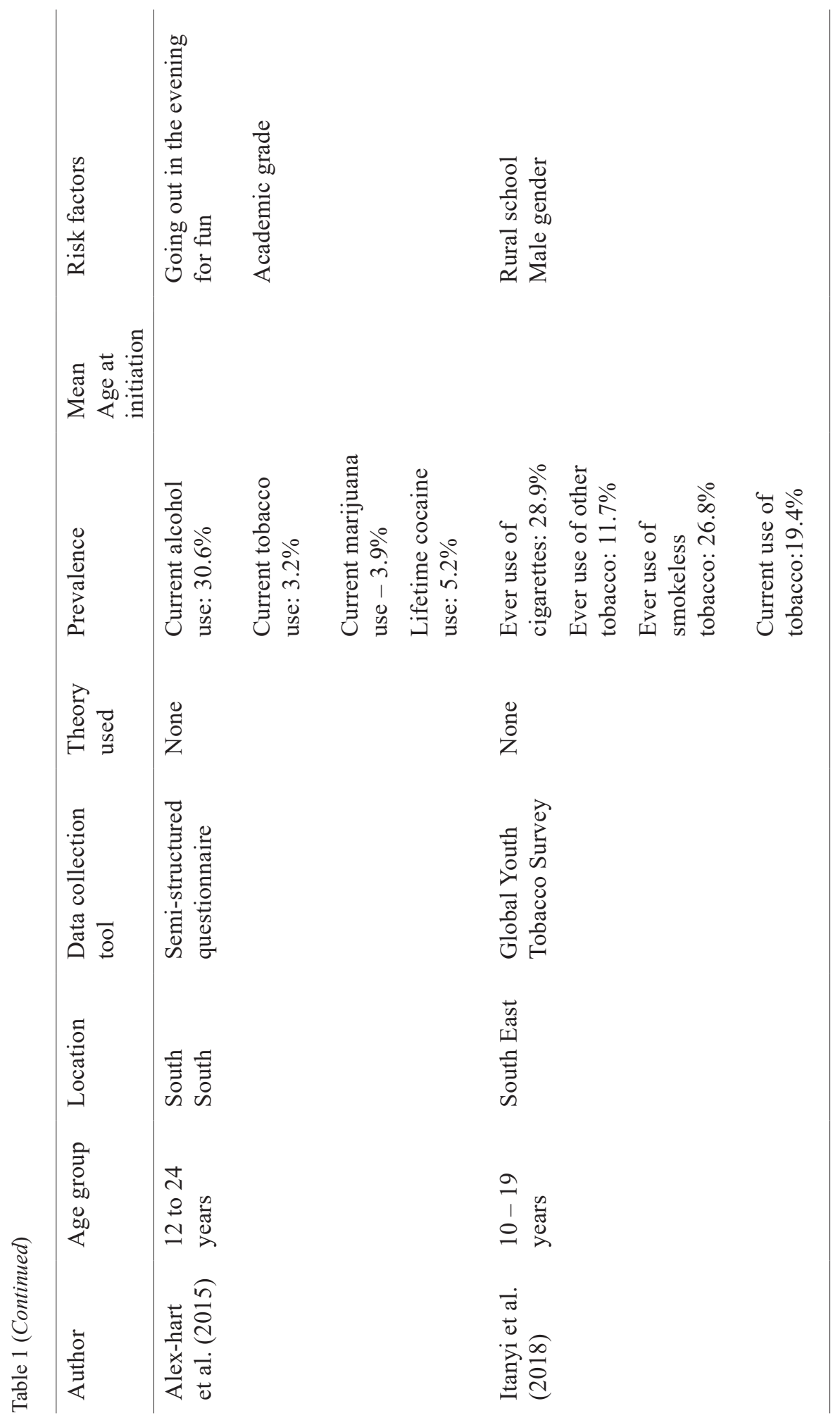




\section{Study Location}

Seven studies were carried out in the SouthWestern part of Nigeria (Atoyebi \& Atoyebi, 2013; Famuyiwa et al., 2011; Idowu et al., 2018; Odukoya et al., 2013; Ogunsola \& Fatusi, 2017; Olugbenga-Bello et al., 2014; Oshodi et al., 2010). Four studies were conducted in the South-South part of Nigeria (Alex-Hart et al., 2015; Arute et al., 2015; Odey et al., 2012; Okagua et al., 2016), four studies in South-Eastern Nigeria (Chinawa et al., 2014; Igwe, 2009; Itanyi et al., 2018; Manyike et al., 2016) and one study in North-Western Nigeria (Raji et al., 2013).

\section{Prevalence of Psychoactive Substance Use}

The prevalence of lifetime psychoactive substance use was found to be high among secondary school students. Oshodi et al. (2010) reported the highest prevalence of psychoactive use among secondary school students at $87.3 \%$. In a different study, about $66 \%$ of students had used at least one form of a psychoactive substance in their lifetime (Ogunsola \& Fatusi, 2017). High lifetime use of substance use was also reported by Atoyebi and Atoyebi (2013) at 52.1\%. Igwe (2009) reported a lower prevalence of psychoactive substance use at $29.5 \%$. Idowu et al. (2018) reported a lifetime substance use of $26.3 \%$, although his definition of substance use did not include alcohol.

\section{Alcohol Consumption}

Several studies reported alcohol as the most used psychoactive substance among secondary school students (Alex-Hart et al., 2015; Igwe, 2009; Manyike et al., 2016; Ogunsola \& Fatusi, 2017; Oshodi et al., 2010).

In the study by Ogunsola and Fatusi (2017), lifetime alcohol use among urban and rural secondary school students was $62.3 \%$ and $58.3 \%$ respectively. Manyike et al. (2016) reported a similarly high lifetime alcohol use of $59.3 \%$. Other authors reported lower lifetime alcohol use at 32.2\% (Famuyiwa et al., 2011), 21.7\% (Idowu et al., 2018), 15.2\% (Atoyebi \& Atoyebi, 2013) and $9.2 \%$ (Oshodi et al., 2010).

On current alcohol consumption, Igwe (2009) reported that $31.6 \%$ of secondary school students used alcohol in the last 12 months with continuing use within the last 30 days preceding the survey. Other authors reported that $8.3 \%$ to $30.6 \%$ of secondary school students consumed alcohol within 30 days preceding the survey (Alex-Hart et al., 2015; Atoyebi \& Atoyebi, 2013; Manyike et al., 2015; Oshodi et al., 2018). In the study by Olugbenga-Bello et al. (2014), 23.1\% admitted to consuming alcohol regularly.

Overall, the prevalence of Nigerian secondary school students who had ever consumed alcohol at least once in their lifetime ranged from $9.2 \%$ to $62.3 \%$, while the prevalence of current alcohol consumers ranged from $8.3 \%$ to $30.3 \%$. However, only two studies reported current alcohol use of less than $10 \%$.

\section{Tobacco Consumption}

Generally, lifetime use of tobacco consumption was lower than lifetime alcohol use. Itanyi et al. (2018) reported 
the highest lifetime prevalence of tobacco use among Nigerian secondary school students as $28.9 \%$ of the students had ever smoked cigarettes, $11.7 \%$ had ever used other forms of tobacco and 26.8\% had ever used smokeless tobacco. Other studies reported lower lifetime prevalence of tobacco consumption ranging from 5.2\% to $11.4 \%$ (Arute et al., 2015; Famuyiwa et al., 2011; Manyike et al., 2016; Okagua et al., 2016; Oshodi et al., 2010).

On current tobacco consumption, the highest prevalence of tobacco consumption in the last 30 days preceding the study was $19.4 \%$ (Itanyi et al., 2018), while two studies reported a prevalence of $14.3 \%$ each (Atoyebi \& Atoyebi, 2015; Igwe, 2009). Other studies reported lower prevalence rates ranging from $2.9 \%$ to $3.5 \%$ (Arute et al., 2015; Manyike et al., 2016; Okagua et al., 2016). Chinawa et al. (2014) reported that $5 \%$ of the students used tobacco for 9 days or less in the past 3 months before the survey, and $3.7 \%$ of them used tobacco products for 10 days or more in the past 3 months before the survey.

Three studies reported on the prevalence of cigarette smoking among Nigerian secondary school students, and thus did not measure other forms of tobacco consumption. Studies by Raji et al. (2013) and Olugbenga-Bello et al. (2014) reported that $16.7 \%$ and $8.3 \%$ of secondary school students were cigarette smokers respectively. Odey et al. (2012) reported that $6.4 \%$ of the students smoked cigarettes in the week preceding the survey, and Alex-hart et al. (2015) reported that $3.2 \%$ of the students were current cigarette smokers who had smoked cigarettes 30 days before the study.

Overall, the prevalence of Nigerian secondary school students who had consumed a form of tobacco at least once in their lifetime ranged from $5.2 \%$ to $28.9 \%$. The percentage of current tobacco consumers ranged from $2.9 \%$ to $19.4 \%$, however in majority of the studies, the prevalence of current tobacco consumption was below $5 \%$.

\section{Cannabis Use}

The lifetime use of cannabis was low compared to lifetime tobacco and alcohol consumption. Igwe (2009) and Oshodi et al. (2010) reported that $4.1 \%$ and $4.4 \%$ of secondary school students had used cannabis at least once in their lifetime, respectively. Alex-Hart et al. (2015) reported a lifetime cannabis use of $3.8 \%$ and Ogunsola and Fatusi (2017) reported lifetime cannabis use of 3\%. Manyike et al. (2016) reported the lowest lifetime prevalence $0.8 \%$.

On current cannabis use, Atoyebi and Atoyebi (2013) reported that $16.7 \%$ of secondary school students had consumed cannabis within 30 days preceding the survey. Other authors reported lower prevalence rates of between 3\% to $4.1 \%$ (Alex-Hart et al., 2015; Igwe, 2009; Ogunsola \& Fatusi, 2017; Oshodi et al., 2010). Manyike et al. (2016) reported the lowest prevalence of current cannabis use at $0.4 \%$.

Overall, the prevalence of lifetime cannabis use among Nigerian secondary school students ranged from $0.8 \%$ to $4.4 \%$. The prevalence of current cannabis use 
among Nigerian secondary school students ranged from $0.4 \%$ to $16.7 \%$, with majority of the studies reporting current cannabis use below $5 \%$.

\section{Cocaine Use}

Studies reported low use of cocaine among secondary school students. Lifetime cocaine use was $4.7 \%$ and $3.8 \%$ as reported by Oshodi et al. (2010) and Famuyiwa et al. (2011) respectively. Alex-Hart et al. (2015) reported a higher prevalence of lifetime cocaine use at $5.2 \%$.

The percentage of current cocaine users who used cocaine within 30 days preceding the survey was $6.4 \%$ (Atoyebi \& Atoyebi, 2013) and 1.9\% (Oshodi et al. 2010).

\section{Mean Age at Initiation of Substance Use}

Of all the studies reviewed, only studies that measured tobacco use reported the mean age at initiation of tobacco or cigarette use. The study by Okagua et al. (2016) reported a mean age of initiation of 12.47 years. In the study by Odukoya et al. (2013), the mean age at initiation of tobacco use was 14.2 years. Raji et al. (2013) reported the highest mean age at initiation of cigarette use as 15.26 years.

\section{Risk Factors of Psychoactive Substance Use}

Sociodemographic characteristics were reported by the reviewed studies as a risk factor for psychoactive substance use among Nigerian secondary school students. Gender was a risk factor mentioned in several studies. In all these studies, males were significantly more likely to use psychoactive substances (Alex-Hart et al., 2015; Famuyiwa et al., 2011; Itanyi et al., 2018; Odey et al., 2012; Odukoya et al., 2013). Age was another sociodemographic characteristic associated with psychoactive substance use. Igwe (2009) however reported that middle aged adolescents were more likely than older and younger adolescents to use psychoactive substances, while in the study by Manyike et al. (2016), adolescents aged 15 to 17 had a significantly higher prevalence of psychoactive substance use compared to those aged 18 and 19 years.

Parental characteristics were a predominant risk factor of psychoactive substance use among Nigerian secondary school students. Secondary school students whose parents used a form of psychoactive substance were significantly more likely to use a substance as well (Atoyebi \& Atoyebi, 2013; Manyike et al., 2016; Odukoya et al., 2013; Okagua et al., 2016; Raji et al., 2013). Ogunsola \& Fatusi (2017) reported that parental disapproval of substance use was a risk factor for substance use among secondary school students. Parental education was another parental characteristic reported to be a significant risk factor of psychoactive substance use (Manyike et al., 2016; Ogunsola \& Fatusi, 2017).

Peer influence was another risk factor associated with psychoactive substances as adolescents with a friend that uses substances were also more likely to use substances (Odukoya et al., 2013; Ogunsola \& Fatusi, 2017; Raji et al., 2013). The reviewed studies also reported certain 
individual characteristics as risk factors of psychoactive substance use. Religious participation was reported by Manyike et al. (2016) as a risk factor of psychoactive substance use. Students with poor academic performance were more likely to use psychoactive substances (Alex-Hart et al., 2015). Additionally, students with a positive attitude towards smoking were more likely to use cigarettes (Odukoya et al., 2013), and students who approved of adult's use of substances were more likely to use psychoactive substances (Ogunsola \& Fatusi, 2017).

Knowledge of the dangers of substance use was a risk factor reported by two studies. In the study by Idowu et al. (2018), those who received formal lectures on the dangers of smoking were less likely to use substances. In the study by Okagua et al. (2016), students with poor knowledge of the harmful effects of smoking were more likely to use cigarettes.

Other risk factors reported by authors were advertisements on tobacco (Okagua et al., 2016), buying cigarettes (Raji et al., 2013), socioeconomic class of the students (Manyike et al., 2016), going out in the evening for fun (Alex-Hart et al., 2015), being in a private school (Ogunsola \& Fatusi, 2017), and living in a rural area (Itanyi et al., 2018).

In several studies, students stated their reasons for using psychoactive substances. They were to have more friends (Raji et al., 2013), to be more intelligent or active (Idowu et al., 2018), to have fun/good time with friends (Alex-Hart et al., 2015; Idowu et al., 2018), to be happy/to feel good (AlexHart et al., 2015; Idowu et al., 2018), peer pressure (Idowu et al., 2018; Okagua et al., 2016), to get relief from stress/forget about worries (Alex-Hart et al., 2015; Arute et al., 2015; Oshodi et al., 2010), to stay awake at night to study/academic purposes (Atoyebi \& Atoyebi, 2013; Oshodi et al., 2010), to be physically fit (Atoyebi \& Atoyebi, 2013), to get sleep/to relax (Alex-Hart et al., 2015), media influence (Okagua et al., 2016), experimentation (Alex-Hart et al., 2015; Okagua et al., 2016), family influence (Okagua et al., 2016), and because they were hooked (Alex-Hart et al., 2015).

\section{DISCUSSION}

This study was conducted to determine the status and risk factors of substance use among secondary school students in Nigeria. The authors also aimed to identify research gaps and recommend strategies for schoolbased interventions.

There were varying differences in methodological definitions of substance use, alcoholic and tobacco consumption across various studies. For example, some studies measured only lifetime use without measuring current use (Famuyiwa et al., 2011; Idowu et al., 2018; Odukoya et al., 2013; Ogunsola \& Fatusi, 2017). Some studies had varying definitions of current use, with one study defining current use as substance use in the 12 months preceding the survey with continuing use within the last 30 days (Igwe, 2009), or as substance use within 30 days preceding the survey (Alex-Hart et al., 2015; Manyike et al., 
2016; Okagua et al., 2016; Oshodi et al., 2010). Additionally, while some studies measured the use of all forms of tobacco (Atoyebi \& Atoyebi, 2013; Chinawa et al., 2014; Famuyiwa et al., 2011; Igwe, 2009; Manyike et al., 2016; Odukoya et al., 2013; Ogunsola \& Fatusi, 2017; Oshodi et al., 2010, 2010), others measured only cigarette use (Alex-Hart et al., 2015; Odey et al., 2012; Okagua et al., 2016; OlugbengaBello et al., 2014). These variations posed a challenge in comparing the prevalence rates of the use of the various psychoactive substances across studies. However, studies that used the WHO Student Drug Use questionnaire provided a form of uniformity in measurement and definition of substance use and allowed for easier comparison.

The studies reviewed reveal a high prevalence of substance use among secondary school students in Nigeria, which is particularly worrisome because substance use can have long-lasting and devastating physical, social, and emotional effects. Accidents, violence, truancy, risky sexual behaviour, poor academic performance, cardiovascular health effects and addiction are some of these effects (Bartal, 2001; Rehm, 2011; Whyte et al., 2018). Thus, it is important that substance use prevention programmes must implemented in secondary schools to prevent its adoption and discourage its use among users.

Several studies reported alcohol to be the most used psychoactive substance among secondary school students. Lifetime alcohol use ranged from $15.2 \%$ to $32.2 \%$, and current alcohol use ranged from $8.3 \%$ to $30.6 \%$. In Nigeria, alcoholic companies sponsor several youth-related events, with young celebrities paid to promote alcoholic drinks. These promotions can influence young Nigerian students who view these celebrities as role models. Moreover, there is currently no written alcohol control policy to regulate the availability of alcohol to adolescents (Dumbili, 2015). As a consequence, secondary school students have unlimited access to alcohol and can easily purchase them without presenting any form of identification as done in other countries.

Although the prevalence of tobacco consumption or cigarette smoking among Nigerian secondary school students is not as high as alcohol consumption, its prevalence is still worrisome. Tobacco is highly addictive and a known risk factor for several cardiovascular diseases and cancers (Bartal, 2001). Moreover, the dangers of second-hand smoke have been well documented (Naeem, 2015). Therefore, the use of tobacco may not be high, nevertheless its use among secondary school students have an impact not only on the smokers themselves, but their friends or peers who may be in close vicinity of those who smoke. The low prevalence of tobacco use could be due to its general unacceptability in Nigeria, as society still perceives cigarette smoking as an act of truancy in Nigeria.

The use of cocaine and cannabis was similarly low. However, considering the highly addictive and dangerous nature of cocaine, it is incredibly worrisome that cocaine is being used among secondary school students. 


\section{Mean Age at Initiation}

The review revealed that the mean age at initiation of psychoactive substance use ranged from 11 to 15 years. In the study by Manyike et al. (2016), the majority of the students reported that their age of first use of alcohol and tobacco ranged from 11 to 14 years. In the study by Arute et al. (2015), it was also reported that the age at initiation of cigarette use was highest between 12 and 15 years. These findings highlight that substance use is initiated early among secondary school students in Nigeria.

\section{Risk Factors of Psychoactive Substance Use}

Parental use of or norm on substances is a risk factor for the use of psychoactive substances among secondary school students. Children are likely to imitate their parents' behaviour, and parents who do not use substances will probably be more likely to disapprove the use of these substances and educate their children on its associated dangers (Ebersole et al., 2014). Additionally, parents who use psychoactive substances may feel like they have poor sources of information on substance use because of the distinction between their attitude and their practices (Raji et al., 2013)

Gender is another unsurprising risk factor for substance use among secondary school students. In Nigeria, males are more likely to experiment and generally have more freedom to leave the house compared to females (Kågesten et al., 2016). This freedom implies less supervision, making it easier for them to adopt the use of psychoactive substances. Additionally, alcohol consumption is generally more tolerated among males in several Nigerian communities but heavily frowned upon when carried out by females (Mamman et al., 2002).

Having a friend that uses a form of psychoactive substances is a risk factor for substance use among secondary school students. Furthermore, having a good time with friends, having fun, peer pressure or wanting to have more friends were reasons secondary school students stated for engaging in substance use. During adolescence, the approval of peers gains more importance, and in secondary schools, adolescents spend more time with their peers than with others (Albert et al., 2013). Hence, they are inclined to adopt similar habits with their or be pressured into adopting these behaviours to fit into a social group.

This review also revealed that knowledge on the dangers of substance use is a risk factor of psychoactive substance use among Nigerian secondary school students. In the study by Oshodi et al. (2010), only $27 \%$ of the secondary school students knew the complications of psychoactive substance use. Additionally, reviewed studies revealed that students used psychoactive substances due to false myths and beliefs such as wanting to be more intelligent (Idowu et al., 2018), believing it is a good way to relieve stress or avoid worries (Alex-Hart et al., 2015; Arute et al., 2015; Oshodi et al., 2010) and stay awake (Atoyebi \& Atoyebi, 2013; Oshodi et al., 2010). These beliefs highlight the importance of proper and 
health education on psychoactive substances in schools.

Students cited reasons for using psychoactive substances such as to relieve stress and be free from worries (Alex-Hart et al., 2015; Arute et al., 2015; Oshodi et al., 2010), be happy, have fun (Alex-Hart et al., 2015; Idowu et al., 2018). More positive and healthy ways of having fun should be promoted in schools. Secondary schools in Nigeria have begun to de-emphasise extracurricular activities and play. Adolescents need a way to express their playful and creative sides to relieve the stress that comes with school learning. Schools need to involve students in engaging, and healthy activities to discourage them from resorting to psychoactive substances to gain these benefits.

\section{Research Gaps}

The authors identified several research gaps while conducting this review.

There were fewer published studies conducted on the use of substances by secondary school students after 2009, implying that there are fewer current studies on this topic in the country. With the current development of the tobacco control policy, the banning of codeine, the observed rising trend of shisha and the westernisation of values, there is an urgent need for more research in this area. Additionally, only two studies reported the use of cough medication among Nigerian secondary school students (Famuyiwa et al., 2011; Ogunsola \& Fatusi, 2017). Currently, there is a rise in the abuse of cough medication by Nigerian youths, with various media houses reporting on a codeine and tramadol crisis overtaking Nigerian youths (BBC, 2018a). This led to the recent ban on the importation and production of codeine by the Nigerian government (BBC, 2018b). It will be interesting to see if this strategy leads to a reduction of its use, hence the need for more recent research on codeine and tramadol use among adolescents.

This review highlights a huge regional gap in the study of psychoactive substances among secondary school students, with few published studies conducted in Northern Nigeria. Northern Nigeria has a different predominant religion and culture from the Southern parts of the country. This cultural and religious climate may influence the use of the varying forms of psychoactive substances. For example, Islam is the predominant religion in Northern states, and it forbids the consumption of alcohol, which may affect the use of alcohol in these regions. Hence, whereas this review reported alcohol as the most abused form of psychoactive substances, it may be a completely different scenario in the Northern states. There, therefore, needs to be more studies on psychoactive substance use in these parts of the country to provide a balanced and comprehensive evidence on the current status of psychoactive substance use in the country.

Another significant gap observed was the lack of use of a theory to guide any of the studies reviewed, although the study by Raji et al. (2013) used a theory to support its findings. Several theories explain the use of 
psychoactive substances among adolescents and can help guide the researchers on the variables to be studied. The lack of use of theory to guide research may be the reason many of the studies focused mainly on sociodemographic variables. While knowledge on the relationship between sociodemographic factors and psychoactive substances is necessary, there is a need to look beyond these factors and study psychological, school-related and community-related factors as well. Perhaps risk factors such as self-esteem, religiosity, confidence, resilience, and efficacy may influence on psychoactive substance use in Nigeria, and it is when we know their effects that interventions can begin to address them. Hence, future research should endeavour to study these possibly related factors.

Finally, all the studies reviewed were cross-sectional studies hence a temporal relationship between independent and outcome variables cannot be ascertained.

\section{Recommendations for School-Based Interventions in Nigeria}

Based on the findings from the reviews, we recommend the following for school-based interventions.

Interventions should focus on all forms of substance use among adolescents. Although this study reports that alcohol is the most consumed psychoactive substance among Nigerian secondary school students, other dangerous psychoactive substances are still consumed. The early age at initiation of substance use highlights the importance of early interventions that target young children yet to initiate the use of psychoactive substances and encourages early users to quit before they get addicted.

There is also a need for interventions to include a family-related component, as the study shows that parental factors influence the use of psychoactive substances. These interventions should inform parents of the need to discourage its use among their children or wards. It is also essential for school-based interventions to include a health education component that addresses the myths associated with the use of psychoactive substances, as some students reported that they used psychoactive substances to become more intelligent, to stay at wake at night and to be active. Finally, school-based interventions should incorporate fun, interactive sessions and teach students healthy ways to relieve stress and have fun.

\section{Study Weaknesses}

This review may have missed relevant studies; however, a thorough literature search of major databases was conducted to minimise this possibility. Additionally, unpublished studies were not included in the review. Finally, not all types of psychoactive substances were included in the review as other forms of substance use such as kola nut and paracetamol were not included.

\section{CONCLUSION}

There is a high prevalence of substance use among Nigerian secondary school students, with an early age at initiation. Gender, age, parental factors, peer factors, 
individual factors, and knowledge on the dangers of substance use are risk factors of substance use among secondary school students. School-based interventions need to be multifaceted and include peer education, family-based, health education, and interactively fun components. There is a need for more research on psychoactive substance use among Nigerian secondary school students, as well as in Northern parts of the country. Future research should be theory-based and measure other psychological and school-related factors.

\section{ACKNOWLEDGEMENT}

I would like to express my special thanks of gratitude to my supervisory committee while I completed my article.

\section{REFERENCES}

Albert, D., Chein, J., \& Steinberg, L. (2013). Peer influences on adolescent decision making. Current Directions in Psychological Science, 22(2), 114120. doi: 10.1177/0963721412471347.

Alex-Hart, B. A., Opara, P. I., \& Okagua, J. (2015). Prevalence of alcohol consumption among secondary school students in Port Harcourt, Southern Nigeria. Nigerian Journal of Paediatrics, 42(1), 39-45. doi: 10.4314/njp. v42i1.9

Arute, J., Oyita, G., \& Eniojukan, J. (2015). Substance Abuse among Adolescents: 2. Prevalence and patterns of cigarette smoking among senior secondary school students in Abraka, Delta State, Nigeria. IOSR Journal of Pharmacy, 5(1), 40-47.

Atoyebi, O. A., \& Atoyebi, O. E. (2013). Pattern of Substance Abuse among Senior Secondary
School Students in a Southwestern Nigerian City. International Review of Social Sciences and Humanities, 4(2), 54-65.

Bartal, M. (2001). Health effects of tobacco use and exposure. Monaldi Archives for Chest Disease, 56(6), 545-554.

BBC. (2018a, May 2). Sweet Sweet Codeine - inside Nigeria's deadly cough syrup trade. BBC Africa's Investigation Unit, Africa Eye. Retrieved May 29, 2020, from https://www.bbc.com/news/ world-africa-43982302.

BBC. (2018b, May 1). Nigeria bans all codeine cough syrup. BBC News. Retrieved May, 29 2020, from https://www.bbc.com/news/worldafrica-43961738.

Center for Substance Abuse Treatment. (1999). Chapter 1-Substance use among adolescents. Treatment of adolescents with substance use disorders (pp. 1-7). Rockville, Maryland: SAMHSA.

Chinawa, J. M., Manyike, P. C., Obu, H. A., Odetunde, O. I., Aniwada, E. C., Ndu, I. K., \& Chinawa, A. T. (2014). Behavioral disorder amongst adolescents attending secondary school in Southeast Nigeria. Behavioural Neurology, 2014, 1-10. doi: 10.1155/2014/705835

Dumbili, E. W. (2015). A review of substance use among secondary school students in Nigeria: Implications for policies. Drugs: Education, Prevention and Policy, 22(5), 387-399. doi: $10.3109 / 09687637.2015 .1041455$

Ebersole, D. S., Miller-Day, M., \& Raup-Krieger, J. (2014). Do actions speak louder than words? Adolescent interpretations of parental substance use. Journal of Family Communication, 14(4), 328-351. doi: 10.1080/15267431.2014.945699

Famuyiwa, O., Aina, O. F., \& Bankole-Oki, O. M. (2011). Epidemiology of psychoactive 
drug use amongst adolescents in metropolitan Lagos, Nigeria. European Child \& Adolescent Psychiatry, 20(7), 351-359. doi: 10.1007/ s00787-011-0180-6

Henry, J. A. (2000). Metabolic consequences of drug misuse. British Journal of Anaesthesia, 85(1), 136-142. doi: 10.1093/bja/85.1.136

Idowu, A., Aremu, A. O., Olumide, A., \& Ogunlaja, A. O. (2018). Substance abuse among students in selected secondary schools of an urban community of Oyo-state, South West Nigeria: Implication for policy action. African Health Sciences, 18(3), 776-785. doi: 10.4314/ahs. v18i3.36

Igwe, W. (2009). Socio-demographic correlates of psychoactive substance abuse among secondary school students in Enugu, Nigeria. European Journal of Social Sciences, 12(2), 1-7.

Itanyi, I. U., Onwasigwe, C. N., McIntosh, S., Bruno, T., Ossip, D., Nwobi, E. A., ... \& Ezeanolue, E. E. (2018). Disparities in tobacco use by adolescents in Southeast, Nigeria using global youth tobacco survey (GYTS) approach. BMC Public Health, 18(1), 1-11. doi: 10.1186/s12889-018-5231-1

Izenwasser, S. (2005). Differential effects of psychoactive drugs in adolescents and adults. Critical Reviews in Neurobiology, 17(2), 51-68. doi.org/10.1615/critrevneurobiol.v17.i2.10

Kågesten, A., Gibbs, S., Blum, R. W., Moreau, C., Chandra-Mouli, V., Herbert, A., \& Amin, A. (2016). Understanding factors that shape gender attitudes in early adolescence globally: A mixedmethods systematic review. PLOS ONE, 11(6), 1-36. doi: 10.1371/journal.pone.0157805.

Mamman, L. S., Brieger, W. R., \& Oshiname, D. P. H. F. O. (2002). Alcohol consumption pattern among women in a rural Yoruba community in Nigeria. Substance Use \& Misuse, 37(5-7), 579-597. doi: 10.1081/ja-120004274
Manyike, P. C., Chinawa, J. M., Chinawa, A. T., Obu, H. A., Nwokocha, A. R. C., \& Odetunde, O. I. (2016). Correlates for psycho-active substance use among boarding secondary school adolescents in Enugu, South East, Nigeria. BMC Pediatrics, 16(1), 2-8. doi: 10.1186/s12887016-0615-9

Naeem, Z. (2015). Second-hand smoke - ignored implications. International Journal of Health Sciences, 9(2), 5-6. doi: 10.12816/0024103

Odey, F. A., Okokon, I. B., Ogbeche, J. O., Terver, G., \& Ekanem, E. E. (2012). Prevalence of cigarette smoking among adolescents in Calabar city, south-eastern Nigeria. Journal of Medicine and Medical Sciences, 3(4), 237-242.

Odukoya, O. O., Odeyemi, K. A., Oyeyemi, A. S., \& Upadhyay, R. P. (2013). Determinants of smoking initiation and susceptibility to future smoking among school-going adolescents in Lagos State, Nigeria. Asian Pacific Journal of Cancer Prevention, 14(3), 1747-1753. doi: 10.7314/apjcp.2013.14.3.1747

Ogunsola, O. O., \& Fatusi, A. O. (2017). Risk and protective factors for adolescent substance use: A comparative study of secondary school students in rural and urban areas of Osun State, Nigeria. International Journal of Adolescent Medicine and Health, 29(3), 1-11. doi: 10.1515/ ijamh-2015-0096

Okagua, J., Opara, P., \& Alex-Hart, B. A. (2016). Prevalence and determinants of cigarette smoking among adolescents in secondary schools in Port Harcourt, Southern Nigeria. International Journal of Adolescent Medicine and Health, 28(1), 19-24. doi: 10.1515/ijamh-2014-0066

Olugbenga-Bello, A. I., Adebimpe, W. O., Akande, R. O., \& Oke, O. S. (2014). Health risk behaviors and sexual initiation among in-school adolescents in rural communities in Southwestern Nigeria. 
International Journal of Adolescent Medicine and Health, 26(4), 503-510. doi: 10.1515/ ijamh-2013-0326

Oshodi, O. Y., Aina, O. F., \& Onajole, A. T. (2010). Substance use among secondary school students in an urban setting in Nigeria: Prevalence and associated factors. African Journal of Psychiatry, 13(1), 52-57. doi: 10.4314/ajpsy.v13i1.53430

Patton, G. C., Sawyer, S. M., Santelli, J. S., Ross, D. A., Afifi, R., Allen, N. B., ... \& Viner, R. M. (2016). Our future: A Lancet commission on adolescent health and wellbeing. The Lancet, 387(10036), 2423-2478. doi: 10.1016/S01406736(16)00579-1

Raji, M. O., Abubakar, I. S., Oche, M. O., \& Kaoje, A. U. (2013). Prevalence and determinants of cigarette smoking among in school adolescents in Sokoto Metropolis, North West Nigeria. International Journal of Tropical Medicine, 8(3), 81-86.
Rehm, J. (2011). The risks associated with alcohol use and alcoholism. Alcohol Research \& Health, 34(2), 135-143.

Squeglia, L. M., Jacobus, J., \& Tapert, S. F. (2009). The influence of substance use on adolescent brain development. Clinical EEG and Neuroscience, 40(1), 31-38. doi: $10.1177 / 155005940904000110$

Viner, R. M., Ross, D., Hardy, R., Kuh, D., Power, C., Johnson, A., ... \& Batty, G. D. (2015). Life course epidemiology: Recognising the importance of adolescence. Journal of Epidemiology and Community Health, 69(8), 719-720. doi: 10.1136/jech-2014-205300

Whyte, A. J., Torregrossa, M. M., Barker, J. M., \& Gourley, S. L. (2018). Editorial: Long-term consequences of adolescent drug use: Evidence from pre-clinical and clinical models. Frontiers in Behavioral Neuroscience, 12, 1-3. doi: 10.3389/fnbeh.2018.00083 
